\title{
Community Based Pilot Study of Diagnostic Paths to the Gluten Free Diet
}

\author{
Joan C. Stevenson ${ }^{1, *}$, Kelle Rankin-Sunter ${ }^{2}$, Crystal Maki ${ }^{1}$, Sean Bruna ${ }^{1}$, MJ Mosher ${ }^{1}$, Christopher E. Barrett ${ }^{1}$ \\ ${ }^{1}$ Anthropology Department, Westerm Washington University, Bellingham, Washington, U.S.A. \\ ${ }^{2}$ Bellingham Gluten Information Group, Bellingham, Washington, U.S.A. \\ *Corresponding author: Joan.Stevenson@wwu.edu
}

Received January 12, 2015; Revised January 15, 2015; Accepted January 19, 2015

\begin{abstract}
Wheat consumption is increasing worldwide and also increasing is the frequency of celiac disease (CeD), a pathological response to wheat protein (gluten) in genetically susceptible individuals. Non-celiac gluten sensitivity (NCGS) is another, less studied wheat-induced pathology. The treatment for both is a gluten-free diet (GFD). More individuals choose the diet than predicted by the epidemiological 1-2\% prevalence. A preliminary survey by questionnaire asked members and attendees of the local gluten information group (GIG) meetings and functions about their diagnostic experiences and symptom levels in order understand the increased demand for gluten-free foods. Same-aged and -sex friends participated as a comparative "control". Mixed methods were used including content analyses of prose narratives and independent and paired $t$ tests of symptom levels measured with Likert scales. This convenience sample, surveyed in 2011-2012, is mostly female (54 F, 5 M) with an average age of $54.6 \pm 2.0$ years. Most participants consulted medical professionals with mean time to diagnosis of 7 years determined mostly from "classic" presenting symptoms. Negative biopsies or blood tests and atypical symptoms that overlap other conditions delayed diagnosis. There were 43 and 16 participants with CeD and NCGS, respectively differing little in symptom levels. Self-diagnosis and use of naturopaths account for some of the "excess" individuals. General practitioners should be encouraged to get additional nutrition training and to discuss with patients dietary choices that support wellness and minimize the risk for pathological immune responses. Patients with $\mathrm{CeD}$ particularly need support and follow-up in the transition to a GFD.
\end{abstract}

Keywords: presenting symptoms, medically unexplained conditions, chronic fatigue, autoimmune thyroiditis

Cite This Article: Joan C. Stevenson, Kelle Rankin-Sunter, Crystal Maki, Sean Bruna, MJ Mosher, and Christopher E. Barrett, “Community Based Pilot Study of Diagnostic Paths to the Gluten Free Diet.” International Journal of Celiac Disease, vol. 3, no. 1 (2015): 17-24. doi: 10.12691/ijcd-3-1-7.

\section{Introduction}

Wheat is the top cereal grain grown, traded and eaten globally in 2012 and demand for wheat continues to increase. [1] Western foods are gaining popularity worldwide, and the most popular foods are wheat-based pasta and pizza. [2] However, wheat and cereals are late additions to the hominin diet [3] Incompletely digested seed storage proteins from wheat (gluten), as well as similar proteins in rye (secalins) and barley (hordeins) can trigger immune responses that lead to damage of the small bowel mucosa in genetically vulnerable individuals. [4,5] Continued irritation interferes with absorption of nutrients and can lead to the autoimmune disorder, celiac disease (CeD), and malignancies such as non-Hodgkin's lymphoma.

$\mathrm{CeD}$ is the most commonly diagnosed of the immunerelated disorders, with a prevalence of at least 1 to $2 \%$ globally and is increasing. [6,7,8,9] $\mathrm{CeD}$ was initially considered a childhood disorder but it is more commonly diagnosed in adults. [10,11] Non-Celiac Gluten sensitivity (NCGS) has been verified to be another condition potentially separate from $\mathrm{CeD}$, and includes individuals who also react to gluten. [12,13,14,15,16] Diagnosis of a gluten-triggered pathology is more likely if the individual reports “classic symptoms” such as diarrhea, fatty stools, and bowel pains, and displays anemia, osteoporosis, and vitamin deficiencies (e.g., B9, B12). [17,18] Most with gluten-triggered reactions may experience symptoms shared with other disorders such as constipation, neurological signs, weight loss, obesity, dyspepsia, depression and anxiety. [11] CeD is confirmed for some health care practitioners only after a biopsy of the villi of the small intestine, the "gold standard" of celiac diagnosis [17].

Individuals with pathological responses to wheat are advised to follow the only known treatment at this time, a gluten-free diet (GFD). [18] A GFD has the potential to reverse some of the damages to the gut and other regions of the body. [19] Surprisingly, the growth of the market for gluten free products far exceeds that predicted by the $1-2 \%$ prevalence for CeD [20] Some of these purchases may reflect people following a new "fad diet" [21] but there may be additional reasons for the increased sales of gluten-free products. a) More individuals with nonclassical CeD may be getting diagnosed. b) Individuals may be self-diagnosing [22] c) More individuals with symptoms that overlap several disorders may become 
frustrated with the lack of any diagnosis and seek diagnoses from alternative physicians. Naturopaths have significantly more training in nutrition and may be diagnosing this condition more readily than practitioners of biomedicine [23].

Some physicians are slow to diagnose because of concerns about adopting a GFD when the alternative foods are not enriched with the added minerals and vitamins typical of many wheat-based products. [21,24,25,26] Sales of these products continue to increase in spite of doubts about the health risks of the GFD. [27] The local Bellingham Gluten Information Group (BGIG) educates affected individuals about $\mathrm{CeD}$ and the GFD. Members and individuals who attend the functions believe they are affected pathologically by wheat. The goal here is to better understand how individuals committed to the GFD are diagnosed, learn about the diet and what they perceive to be benefits of the diet. Patterns in the diagnostic trajectories of individuals may help explain why there is an excess of individuals purchasing gluten-free products.

\section{Methods}

\subsection{Study Population}

Bellingham, Washington is 90 miles north of Seattle, and about 50 miles south of the Canadian border. It is home to three universities, has a strong agricultural economic base and a variety of non-farm businesses. As of April 2013 population size for Bellingham, Washington was 82,310, less than half of the total for Whatcom County at more than 205,000. Whatcom County is predominantly "white" but diversity is increasing and includes $8 \%$ of Hispanic origin and 3\% representing two federally recognized tribes, Lummi and Nooksack. [28] The county also has a relatively higher proportion of older citizens. Whatcom County is considered by the federal government to be a Health Professional Shortage Area due to the inadequate numbers of primary care providers. The study population included adults at least 18 years of age who were members of or attended a GIG function, and believed they were affected pathologically by wheat and followed a GFD.

\subsection{Data Collection}

The questionnaire, consent form, and sample design were approved for an exemption by the Human Subjects Internal Review Board at Western Washington University. A detailed questionnaire was constructed with the leadership of the BGIG led by Rankin-Sunter. Participants indicated how often they ate wheat-based foods, and also provided information on background variables including demographic, travel and gastrointestinal issues, and the diagnostic process. A list of present symptoms was adapted from the instrument described by Leffler et al. [29] The frequency of symptoms--before diagnosis, after switching to a GFD, and in the last 4 weeks--were assessed by the participants relative to frequency (Likert scale): none (1), a little of the time (2), some of the time (3), most of the time or (4), all of the time (5).

The diagnostic trajectory information was solicited by the following questions: The diagnostic process was started by (please circle all that apply): self, relative, friend, medical professional. Can you supply any other details about the context that started the diagnostic process? How many and what kinds of medical professionals did you consult? Please provide dates (or rough timing) for the steps in the process (Timeline?).

\subsection{Data Analysis}

Mixed methods were used. Qualitative narratives were assessed by content analysis. The symptom levels for all or subsamples of the participants were summarized by means and standard errors. All statistical analyses were performed using Statistical Package for the Social Sciences (PASW 18). The average scores "summarized" the typical responses per question and are compared using either independent or paired t tests, the former adjusted for unequal variances when necessary.

\section{Results}

\subsection{Study Population}

The research was described at a Bellingham GIG meeting on March 1, 2011, during which questionnaires were distributed. They were also available at a GIG cosponsored educational and gluten-free food sample distribution at a shopping center on October 21, 2011. Questionnaires were available at meetings thereafter until December 30, 2012. The majority of participants were members of the GIG and students from the local universities and at least $46 \%$ of them returned the questionnaires. A few individuals were recruited through an on-line referral attached to the GIG web site. Friends were recruited by participants if they were the same sex and close in age and willing to fill out the questionnaire regarding background information, symptoms and comorbid pathologies. Thirty three of the "friends" returned the questionnaires.

Intestinal damage can occur for other reasons and lead to similar symptoms (e.g., tropical sprue). [30] Participants were asked whether they traveled outside the country and were sick, the context, and whether the experience or incident affected current health. Questions also concerned illness relative to consumption of foods in the USA. Nine participants did not travel outside of the USA. Thirty-one participants had traveled or lived outside of the USA with no problems but six felt they had always reacted to food. Nineteen participants $(61.3 \%$ of those who traveled) recalled illnesses during travel outside of the USA. Contexts varied but typically the out of country illness was either similar to lifelong discomforts or the illness was temporary with no long-lasting effects. Travel outside of the country did not seem to trigger the discomforts that were reported.

\subsection{Demographics}

Table 1 summarizes the demographic information for both the participants and friends of the participants. Both samples are predominantly European descent, mostly married, mostly female (54 F, $5 \mathrm{M}$ ) and range in age from 20 years to late 80 s with an average of $54.6 \pm 2.0$ years. Only 12 individuals are less than 46 years. The participants are highly educated and relatively economically well off 
with more than $50 \%$ of participants and friends making more than 50 thousand dollars a year.

Table 1. Background Characteristics of Participants and Friends

\begin{tabular}{|l|l|l|l|l|}
\hline & $\mathrm{N}$ & Partic & $\mathrm{N}$ & Friends \\
\hline Sex & 59 & $\%$ & 32 & $\%$ \\
\hline Males & 5 & 8.5 & 3 & 9.40 \\
\hline Females & 54 & 91.5 & 29 & 90.60 \\
\hline Ancestry & 54 & $\%$ & 29 & $\%$ \\
\hline European & 53 & 98.0 & 27 & 97.00 \\
\hline African & 1 & 2.0 & 0 & 0.00 \\
\hline Native Am. & 0 & 0.0 & 1 & 3.50 \\
\hline Education & 59 & $\%$ & 30 & $\%$ \\
\hline H S Diplo. & 2 & 3.4 & 3 & 10.00 \\
\hline Some College & 14 & 23.7 & 8 & 26.70 \\
\hline Bachelors & 21 & 35.6 & 7 & 23.30 \\
\hline Bachelors + & 7 & 11.9 & 3 & 10.00 \\
\hline Ms Degree & 12 & 20.3 & 9 & 30.00 \\
\hline Ph.D. & 3 & 5.1 & 0 & 0.00 \\
\hline Age & 59 & & 31 & \\
\hline Range (yrs) & & $20-89$ & & $20-88$ \\
\hline Ave \pm S. E. & & $54.6 \pm 2.0$ & & $50.4 \pm 3.3$ \\
\hline Marital Status & 59 & $\%$ & 32 & $\%$ \\
\hline Single & 11 & 18.6 & 5 & 13.30 \\
\hline Married & 40 & 67.8 & 20 & 63.30 \\
\hline Divorced & 2 & 3.4 & 1 & 3.30 \\
\hline Share Residence & 3 & 5.1 & 2 & 6.70 \\
\hline Widowed & 3 & 5.1 & 4 & 13.30 \\
\hline Occupation & 59 & $\%$ & 32 & $\%$ \\
\hline Educators & 12 & 20.3 & 6 & 18.75 \\
\hline Business & 4 & 6.8 & 3 & 10.00 \\
\hline Professional & 9 & 15.3 & 2 & 6.24 \\
\hline Trades & 3 & 5.1 & 0 & 0.00 \\
\hline Servic/Housewif & 7 & 11.9 & 8 & 0.25 \\
\hline Health Prof & 4 & 6.8 & 1 & 0.03 \\
\hline Retired & 15 & 25.4 & 9 & 0.28 \\
\hline Stud/unempl & 5 & 8.5 & 3 & 10.00 \\
\hline Household Inc & 55 & $\%$ & 32 & $\%$ \\
\hline \$0-24,999 & 8 & 14.5 & 5 & 15.63 \\
\hline 25,000-49,999 & 11 & 20.0 & 11 & 34.38 \\
\hline $50,000-74,999$ & 17 & 30.9 & 7 & 21.88 \\
\hline $75,000-99,999$ & 10 & 18.2 & 6 & 18.75 \\
\hline 100,000+ & 9 & 16.4 & 3 & 9.36 \\
\hline
\end{tabular}

\subsection{Presenting Symptoms}

Sufficient details about the presenting symptoms were provided by 49 out of the 59 participants (83.1\%). Fifty five percent $(\mathrm{N}=29)$ of the 49 individuals presented with mostly "classic" symptoms such as: "constant GI problems" (\#1), "blood in stool, pain, urgency, etc. related to B. M. [bowel movement], had several colon polyps removed via colonoscopy" (\#2); “upset stomach, joint pains, bathroom runs within an hour of consuming gluten”
(\#7); “acid reflux, thyroid” and so on. Other presenting symptoms included: persistent rashes (likely undiagnosed dermatitis herpetiformis), nutritional deficiencies, recurrent migraines, and frequent sinus infections. Few mentioned cognitive or psychological factors in the lists of presenting symptoms.

\subsection{Diagnostic Trajectories}

The diagnostic process leading to the GFD $(n=56, \%)$ was initiated by medical professional $(18,32.1 \%)$, by participants $(16,28.6 \%)$, by participant and medical professional $(10,17.9 \%)$, at the urging of a relative (5, $8.9 \%)$, relative and friend $(1,1.8 \%)$, friend $(1,1.8 \%)$, participant, friend or relative and medical professional (5, 8.9\%). In 7 cases, having affected relatives meant that you were more likely to self-diagnose. Participants were considered to be self-diagnosed if consultation with health care professionals was not mentioned. Others stated: "I self-diagnosed because my sister was diagnosed about 20 years before me, and I began having classic symptoms (diarrhea)" (\#6).

Participants were usually referred by their primary physician (general practitioner, osteopath, or naturopath) to: most commonly, a gastroenterologist, followed by dietician/nutritionist, and allergist. Additional health care professionals consulted less often included chiropractor, psychiatrist, internist, acupuncturist, herbalist, massage therapist, counselor, obstetrician/gynecologist, surgeon, neurologist, optometrist or ophthalmologist, dermatologist, and cardiologist. One participant mentioned seeing both military as well as civilian doctors. There was little to indicate coordinated efforts among the specialists other than the initial referrals.

Tests per individual ranged from 0 to 11 and included screening for the risk genes, levels of immune response in blood, stool and saliva, upper and lower gastrointestinal series with cameras, and biopsy. A few individuals were subjected to skin tests for specific allergens including foods. Tests not directly used to diagnose gluten pathologies included measurement of hormone levels, urine metabolites, and a sleep study for one individual. Several were subjected to CAT scans, MRI's or ultrasounds. One participant narrowly avoided exploratory surgery.

Forty-three participants (72.9\%) were classified consistent with symptoms and/or medical professional diagnosis with CeD and 16 (27.1\%) with NCGS (after a negative antibody test or biopsy). Thirty-three (55.9\%) individuals were diagnosed on the basis of either blood tests or biopsy; 9 (15.3\%) were diagnosed by positive tests in both. Twenty-four (40.7\%) participants were diagnosed either partly or fully by elimination diet. Most $(\mathrm{N}=41$, $69.5 \%$ ) were the first in their families to be identified with a gluten-triggered condition, and 18 (30.5\%) were diagnosed after referrals from: sister (5), brother (2), daughter (2), niece (1), and family (2). Fourteen (23.7\%) participants consulted naturopathic physicians, a group for which diet is part of the initial interview [23].

\subsection{Treatment Strategies}

Most participants were told not to eat gluten-containing foods but only 7 mentioned referral to nutritionists or dieticians. Naturopathic physicians routinely discuss 
nutrition and diet, possibly eliminating the need for a referral to a nutritionist or dietician for the 14 participants that consulted naturopathic physicians. Other participants apparently made the diet change without such support. For example: "Diagnosis not clear, doctor just told me to stop eating gluten” (\#2); “I didn’t have problems switching over because I didn't eat a lot of the products. Ate a ricebased diet, veggies, just made adaptions to what I did. Had more problems when giving up dairy" (\#7); “Due to number of [food] sensitivities virtually almost impossible to find something” (\#8); “tested for 96 foods, sensitive to 27” (\#10). Participants with several coincident conditions were less likely to view gluten as their primary problem.

Avoiding consumption of gluten is a high priority for all 59 participants; 81.4\% $(\mathrm{N}=48)$ of the participants in this sample claim to eat gluten only accidentally and $93.2 \%$ (55) report that they did not eat any food "when in doubt". This is a highly motivated and educated sample. Cost of the GFD is stated to not be a problem. The proxy for time on GFD is calculated as age at diagnosis minus age at time of filling out the questionnaire and averaged
$6.56 \pm 1.15$ years. Thirty-seven percent of the participants had been on the diet for 3 years or less but there are statistically significant differences between being on the GFD 3 years or less vs. 4 years or more for only pre-GFD symptom levels $(\mathrm{t}=-2.02 \mathrm{p}=0.05$ degrees of freedom $=$ 44) and no significant differences in total symptoms or symptoms in the last month. Time on GFD correlates significantly only with age $(r=0.342, p=0.011, \mathrm{~N}=54)$. Correlating negatively with age are total symptoms in the last month $(-0.377, \mathrm{p}=0.01, \mathrm{~N}=46)$ and total symptoms post-GFD (-0.422, $\mathrm{p}=0.003, \mathrm{~N}=46)$.

\subsection{Symptoms Pre- and Post-GFD}

Participants were also asked to indicate which symptoms were experienced prior to and after adjusting to a GFD. Table 2 presents all symptom frequencies in averages with standard errors for the total sample of participants relative to pre-diagnosis versus post-GFD, and for friends.

Table 2. Symptoms Pre- and Post-GFD for Total Sample and Friends

\begin{tabular}{|c|c|c|c|c|c|c|c|c|c|c|}
\hline \multicolumn{8}{|c|}{1 None 2 A little of the time 3 Some 4 Most 5 All of the time } & & & \\
\hline & & -Diagnos & & & Post -GFL & & Sig & \multicolumn{3}{|c|}{ Friends } \\
\hline & \multicolumn{6}{|c|}{ All Affected Part icipants } & & & & \\
\hline Symptoms & $\mathrm{N}$ & Mean & SE & $\mathrm{N}$ & Mean & SE & & $\mathrm{N}$ & Mean & SE \\
\hline Abdom. Disten. & 55 & 2.82 & 0.20 & 50 & 1.60 & 0.11 & 2 & 18 & 1.28 & 0.14 \\
\hline Abdom. Pain & 55 & 3.11 & 0.17 & 50 & 1.63 & 0.09 & 2 & 18 & 1.33 & 0.11 \\
\hline Brain Fog & 55 & 2.76 & 0.19 & 50 & 1.76 & 0.12 & 2 & 18 & 1.83 & 0.20 \\
\hline Bulky stools & 50 & 2.14 & 0.17 & 48 & 1.56 & 0.10 & 2 & 18 & 1.11 & 0.08 \\
\hline Diarrhea & 54 & 2.72 & 0.18 & 47 & 1.53 & 0.10 & 2 & 18 & 1.50 & 0.19 \\
\hline Flatulence & 55 & 3.40 & 0.15 & 50 & 2.08 & 0.11 & 2 & 18 & 1.94 & 0.21 \\
\hline Steatorrhea & 53 & 2.19 & 0.20 & 48 & 1.31 & 0.09 & 2 & 17 & 1.00 & 0.00 \\
\hline Vomiting & 54 & 1.26 & 0.07 & 49 & 1.08 & 0.04 & 1 & 18 & 1.11 & 0.08 \\
\hline Weight Loss & 54 & 2.09 & 0.22 & 49 & 1.51 & 0.14 & 1 & 18 & 1.28 & 0.20 \\
\hline Anemia & 53 & 2.89 & 0.23 & 48 & 1.58 & 0.16 & 2 & 18 & 1.39 & 0.24 \\
\hline Frequent canker sores & 54 & 2.30 & 0.19 & 48 & 1.49 & 0.11 & 2 & 18 & 1.11 & 0.08 \\
\hline Osteoarthritis & 55 & 1.67 & 0.16 & 49 & 1.59 & 0.17 & 2 & 18 & 1.50 & 2.50 \\
\hline Rheumatoid arthritis & 53 & 1.28 & 0.12 & 48 & 1.17 & 0.10 & ns & 17 & 1.06 & 0.06 \\
\hline Chronic fatigue & 53 & 3.38 & 0.21 & 49 & 2.22 & 0.17 & 2 & 18 & 1.50 & 0.22 \\
\hline Constipation & 55 & 2.58 & 0.19 & 49 & 1.82 & 0.14 & 2 & 18 & 1.33 & 0.11 \\
\hline Itchy skin rash & 55 & 2.27 & 0.21 & 51 & 1.55 & 0.11 & 2 & 18 & 1.17 & 0.09 \\
\hline Esophageal reflux & 56 & 2.41 & 0.20 & 52 & 1.81 & 0.14 & 2 & 18 & 1.56 & 0.27 \\
\hline Numb/Pain Hds/Feet & 55 & 2.15 & 0.19 & 50 & 1.88 & 0.17 & 1 & 18 & 1.50 & 0.26 \\
\hline Recurrent abdominal pain & 55 & 2.91 & 0.19 & 50 & 1.72 & 0.11 & 2 & 18 & 1.06 & 0.06 \\
\hline Moodiness & 55 & 2.93 & 0.19 & 51 & 1.75 & 0.12 & 2 & 18 & 1.67 & 0.18 \\
\hline Chronic depression & 55 & 2.36 & 0.20 & 49 & 1.47 & 0.11 & 2 & 18 & 1.22 & 0.13 \\
\hline Frequent sinus congest ion & 53 & 3.17 & 0.22 & 49 & 2.12 & 0.17 & 2 & 17 & 1.59 & 0.27 \\
\hline Vitamin deficiencies & 53 & 2.68 & 0.23 & 46 & 1.91 & 0.18 & 2 & 18 & 1.22 & 0.22 \\
\hline $1 \mathrm{p} \leq 0.05,2 \mathrm{p} \leq 0.01$ & & & & & & & & & & \\
\hline
\end{tabular}

Almost all symptoms decreased statistically significantly in perceived frequency for the total participant sample after switching to a GFD. There were no statistically significant differences between participants with $\mathrm{CeD}$ versus participants with NCGS relative to average: age, months to diagnosis, height, weight, and in frequencies of most symptoms prior to a GFD. The exceptions were higher frequencies of chronic fatigue and chronic depression in participants with $\mathrm{CeD}$ prior to a GFD. Friends had much lower levels of all symptoms relative to 
symptom levels in pre-diagnosis participants and after participants switched to a GFD.

Participants reported lower average scores for all symptoms experienced in the last 4 weeks except for physical pain which was perceived to be the same. Average scores differed statistically significantly between participants diagnosed with CeD versus NCGS for: rumbling in the stomach, bloated stomach, low energy, and for loss of appetite at inappropriate times.

Comorbid conditions are presented in Table 3.

Table 3. Comorbid Conditions

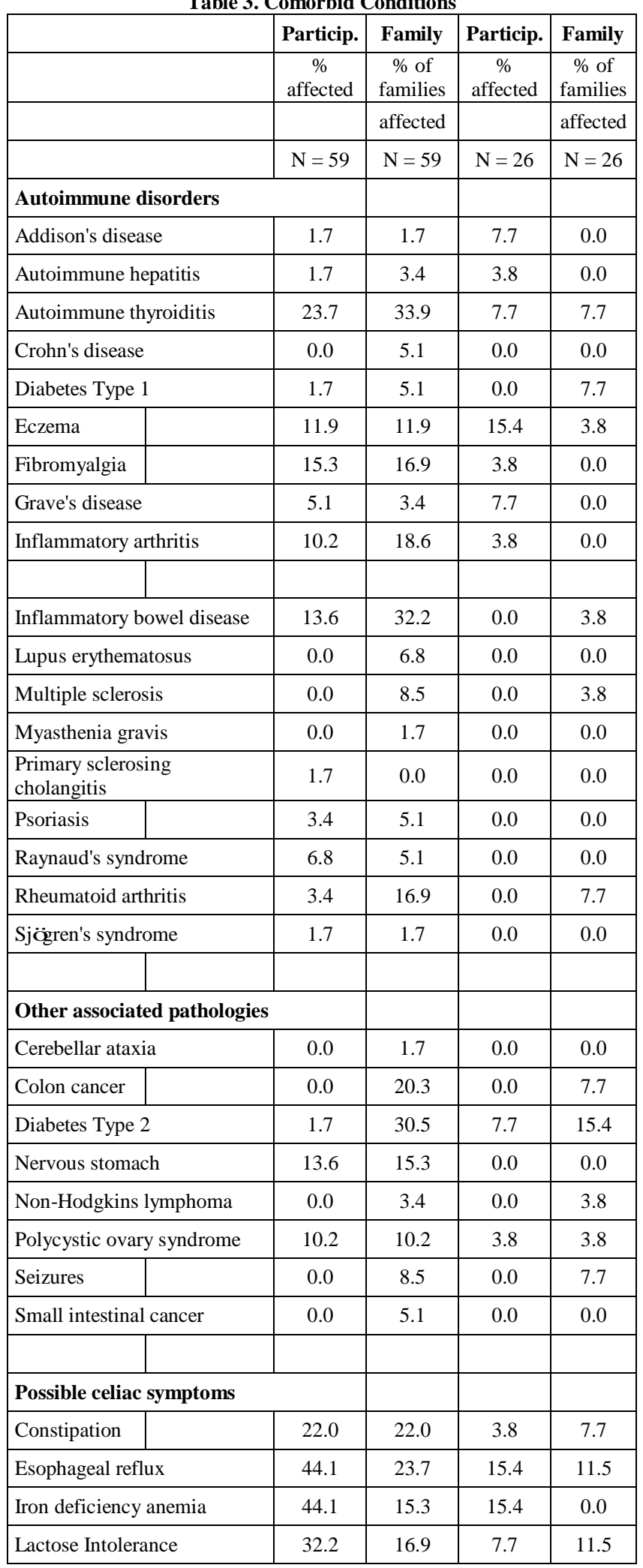

The highest frequencies reported by participants for themselves and their families were for: autoimmune thyroiditis and irritable bowel syndrome followed by inflammatory arthritis. Fatigue and fibromyalgia are also relatively frequent. Family members do not always report illnesses to other family members, and thus, these counts are likely underestimates.

\section{Discussion}

\subsection{Diagnostic Challenges}

Copelton and Valle [22] exhaustively review the diagnostic problems that occur when gluten-triggered responses result in a variety of affected phenotypes along symptom continua that do not always include damage to the intestinal villi. One must be eating gluten in order to be diagnosed either by a blood test or by biopsy but a positive diagnosis is not a certainty due to the variability in the individual's responses to gluten and differences in laboratory testing procedures. [31] The 59 participants in this study are a diagnostically heterogeneous convenience sample but the composition is intended to be more inclusive of the variety of individuals who are pursuing a GFD. The sample composition does mostly match understanding of current epidemiology--mostly female, and older adults [although unusual for research on CeD, a number of which are not tested by blood test or biopsy]. [31,32] Participants and their friends are well-educated and claim that cost of the more expensive GFD is not an issue.

At least (82.4\%) of the participants described some degree of 3 or more of the "classic" gastrointestinal symptoms (stomach pain, diarrhea, etc.) or gastrointestinal pathologies such as polyps. These symptom patterns area also not unique to CeD. [10,11] Most participants here were diagnosed with $\mathrm{CeD}$, based initially on the presence of gastrointestinal symptoms, but many participants reported high levels of extra-intestinal symptoms such as brain fog, moodiness, sinus congestion, and comorbid conditions such as chronic fatigue. This would suggest that it is still the case that "classic" symptoms are still the most salient aspect of discomfort and diagnosis.

\subsection{CeD versus NCGS}

Participants with NCGS did not differ significantly relative to participants diagnosed with $\mathrm{CeD}$ for all the background variables or for the levels of most symptoms. However, participants with NCGS did report statistically significantly lower levels of chronic fatigue and chronic depression pre-GFD. Differences between these two subsamples may be lessened because of the reliance on participants' self-identification of their pathologies. There are likely shared phenotypes between the two subsamples since there is still confusion regarding exactly what NCGS represents-early stages of $\mathrm{CeD}$ or different phenotypes. [13,14,15] Carroccio et al. [33] have provided support for a clinically distinct from CeD diagnostic category that they label non-celiac wheat sensitivity. Their protocol included a double-blind placebo-controlled wheat challenge. They further suggest that there may be two subgroups within the new category, one group that overlaps $\mathrm{CeD}$ and the other indicative of food allergies. 
This may partly account for the phenotypic variability in this sample. Unfortunately the diversity of symptoms means that individuals afflicted with atypical symptoms are also often not identified [34].

The absence of readily identified patterns unique to specific conditions has resulted in literature addressing these challenging, often female patients, whose illnesses are described as medically unexplained conditions and include disorders such as chronic fatigue syndrome, fibromyalgia, and irritable bowel syndrome, conditions elevated relative to friends [35,36] The symptoms among these pathologies overlap with each other and the phenotypic spectrum of CeD. There is no agreement on the biomedical nature of the shared pathology. [37] Patients with these conditions are described as "complex patients" because of the diagnostic difficulties and their many demands on and frustration with the health care system [38].

$\mathrm{CeD}$ and NCGS are systemic and affect many body systems differently and uniquely for each patient and are more likely to manifest as the individual ages but again at a time unique to each patient. [23] The diagnostic process took longer if the participant was negative for a blood test or biopsy. The delayed diagnosis may partly reflect that many allopathic physicians receive limited training in nutrition although most recognize the need for increased nutrition curriculum at medical schools. [39,40,41] Allopathic physicians in this study favored verification of CeD by laboratory testing or a biopsy. The naturopaths recommended elimination diet to diagnose food triggered pathology, and none demanded a biopsy; whereas, two participants mentioned that their general practitioner continued to press for a biopsy in spite of severe "classic" symptoms. Thus, diagnosis of these conditions is still challenging and many affected individuals in both diagnostic categories may be getting missed.

\subsection{Perceived Benefits of GFD}

Most all participants perceived a reduction in symptoms, a finding by others. [13,42] Slow diagnosis prolongs suffering for many affected individuals in some cases for many years (43). The limitations of a GFD would indicate that follow-up of affected individuals is important and medical professionals were consulted by all but 3 participants. [24] However, current follow-up is often inadequate. [44] Negative lab tests delay treatment but individuals with a diagnostically challenging medically unexplained condition might benefit from an early (prediagnosis) discussion of dietary choices and the potential utility of an elimination diet.

Reluctance to pursue a GFD may be partly a function of persisting symptoms, evident in the sample here. That symptoms continue may reflect a number of factors. About $24.5 \%$ of the participants in this study report sharing kitchens with gluten consumers indicating potential cross-contamination. Avoidance is also a challenge outside the home in the USA. Wheat proteins can be hydrolyzed resulting in blends of multiple sizes of polypeptides that can be manipulated to exhibit emulsifying and foaming qualities. [45] These features make these mixtures attractive additives to cosmetics (e.g., facial soap, hair spray, eye shadow, lipsticks, mascara) and food products (e.g., soups, sauces, snacks, meat-based products) but can trigger allergies in affected individuals. Follow-up support should also consider discussions about contamination from nonfoods.

Another reason for continuing symptoms is noted by Tursi et al. [26] in that about 3 percent of GFD-compliant patients with $\mathrm{CeD}$ symptoms do not exhibit recovery while on a GFD and are described as "refractory". The most severe complications lead to increased mortality and include malignancies such as small bowel adenocarcinoma and enteropathy-associated T-cell lymphoma. Dewar et al. [46] noted that 45 out of 100 individuals did not adhere carefully to the GFD. Many did not seem to understand that recovery depends on complete elimination of the offending foods. Half of the non-compliant patients are aware that they are not following the diet adequately but did not admit their "cheating" at the initial interview; this may be an issue for this sample too. Incomplete information at diagnosis and inadequate follow-up reduce compliance with a GFD. [44,46,47,48,49] Some health care personnel seem to have difficulty recognizing food allergies or the importance of strict avoidance. [46,50,51,52] Another complication is the amount of gluten in some gluten-free foods is below a threshold but not absent and can trigger a reaction in vulnerable individuals [53].

The elimination of gluten from diets is occurring worldwide. [54] Reduced inflammation is one significant benefit from adhering to a GFD. [19] Nutritional deficiencies can be identified and remedied given sufficient support. [54] Ma et al. [10] provide a recommended flow chart for pursuing a diagnosis that is more inclusive of the diverse array of phenotypes that reflect pathological responses to gluten. They also downplay the importance of the biopsy.

\section{Conclusions}

Extrapolating from this Bellingham, Washington sample is limited by the potential biases inherent in a small convenience sample but highlighted here are the persisting difficulties in identifying and treating individuals with possible food-triggered pathologies. Patient perceptions about food reactions should be valued as an indicator of at least the need to discuss dietary choices. The intimate relationship between food choices and immune responses, particularly inflammation, may not be appreciated by some clinicians. Comorbid conditions may be triggered by the same altered immune response. Classic symptoms still appear to be the most salient indicator of $\mathrm{CeD}$ and thus, there are still likely many missed individuals, especially if reporting atypical symptoms.

A diagnosis of $\mathrm{CeD}$ was usually verified by lab tests if the physician was allopathic. Naturopaths relied more on elimination diets and patient reports to diagnose $\mathrm{CeD}$ or NGCD. Participants diagnosed with CeD versus participants with NGCD did not differ significantly relative to demographic characteristics or for most symptom levels. Most participants reported a decline in symptoms post-GFD but about $1 / 3$ experienced suspicious symptoms in the last 4 weeks reflecting likely both inadvertent and deliberate exposure to gluten.

Only slightly more than half of this sample was diagnosed by blood tests or biopsy providing evidence for part of the excess individuals committed to a GFD. Forty 
percent were diagnosed using an elimination diet which relies on patient perceptions. Slow diagnosis typically after a negative biopsy or blood test was a source of frustration and many self-diagnosed if contacted by relatives with shared symptoms. Others sought naturopaths who more readily discuss diet and its impact on health. Many were self-diagnosed and there is only one treatment, the GFD, with no need for a prescription. Many feel better not eating wheat which may be due partly to reduced inflammation. However, the persistence of symptoms does indicate a need for more support in the transition and adherence to a GFD. Health care professionals were consulted by most of the participants and have important roles to play before, during and well after diagnosis. We recommend that: 1 ) doctors in the USA may need training in the dynamic between food choices and immune responses; 2) the clinical encounter should include discussions about food, nutrition, and wellness, and 3) patient-centered care may provide opportunities to learn whether adjusted diets are improving patient-wellbeing.

\section{Acknowledgements}

We wish to thank the GIG membership, especially participants and their friends. The Anthropology Department at Westerm Washington University also helped with expenses associated with the questionnaire.

\section{Statement of Competing Interests}

The authors have no competing interests.

\section{List of Abbreviations}

\author{
CeD: Celiac Disease \\ GFD: Gluten Free Diet. \\ NCGS: Non-Celiac Gluten Sensitivity.
}

\section{References}

[1] Khan MI, Anjum FM, Pasha I, Sameen A, Nadeem M, "Nutritional quality and safety of wheat-soy composite flour chapattis,” Brit Food J, 114 (2-3), 239-47, 2012.

[2] GlobeScan, "Grow campaign: global opinion research-final Topline report 20 May 2011 for Oxfam”,

$<$ http://www.oxfam.org/sites/www.oxfam.org/files/growcampaignglobescan-research-presentation.pdf $>$.

[3] Brown TA, Jones MK, Powell W, Allaby RG, "The complex origins of domesticated crops in the Fertile Crescent”, Trends Ecol Evolut, 24 (2), 103-9, Feb 2009.

[4] Abadie V, Sollid LM, Barreiro LB, Jabri B, "Integration of genetic and immunological insights into a model of celiac disease pathogenesis,” Annu Rev Immunol, 29, 493-525, 2011.

[5] Tatham AS, Shewry PR, "The S-poor prolamins of wheat, barley and rye: revisited,” J Cereal Sci, 55 (2), 79-99, Mar 2012.

[6] Catassi C, Kryszak D, Bhatti B, Sturgeon C, Helzlsouer K, Clipp SL, Gelfond D, Puppa E, Sferruzza A, Fasano A, "Natural history of celiac disease autoimmunity in a USA cohort followed since 1974,” Ann Med, 42 (7), 530-8, Oct 2010.

[7] Kang JY, Kang AHY, Green A, Gwee KA, Ho KY, "Systematic review: worldwide variation in the frequency of coeliac disease and changes over time,” Aliment Pharm Therap, 38 (3), 226-45, Aug 2013.

[8] Mustalahti K, Catassi C, Reunanen A, Fabiani E, Heier M, McMillan S, Murray L, Metzger M-H, Gasparin M, Bravi E, Mäki and Members of the Coeliac EU Cluster, Epidemiology, "The prevalence of celiac disease in Europe: results of a centralized, international mass screening project,” Ann Med, 42 (8 ), 587-95. Dec 2010.

[9] Reilly NR, Green PHR, "Epidemiology and clinical presentations of celiac disease,” Sem Immunopathol, 34 (4), 473-8, Jul 2012.

[10] Ma MX, John M, Forbes GM, "Diagnostic dilemmas in celiac disease,” Exp Rev Gastroenterol Hepatol, 7 (7), 643-55, Sep 2013.

[11] Nejad MR, Rostami K, Pourhoseingholi MA, Mojarad EN, Habibi M, Dabiri H, Zali MR, "Atypical presentation is dominant and typical for coeliac disease,” J Gastrointest Liver, 18 (3), 285-91, Sep 2009.

[12] Biesiekierski JR, Newnham ED, Irving PM, Barrett JS, Haines M, Doecke JD, Shepherd SJ, Muir JG, Gibson PR, "Gluten causes gastrointestinal symptoms in subjects without celiac disease: a double-blind randomized placebo-controlled trial,” $\mathrm{Am} \quad J$ Gastroenterol, 106 (3), 508-14, Mar 2011.

[13] Biesiekierski JR, Newnham ED, Shepherd SJ, Muir JG, Gibson PR, "Characterization of adults with a self-diagnosis of nonceliac gluten sensitivity,” Nutr Clin Pract 29 (4), 504-9, Aug 2014.

[14] Brown AC, "Gluten sensitivity: problems of an emerging condition separate from celiac disease,” Exp Rev Gastroenterol Hepatol, 6 (1), 43-55, Feb 2012.

[15] Sapone A, Bai JC, Ciacci C, Dolinsek J, Green PHR, Hadjivassiliou M, Kaukinen K, Rostami K, Sanders DS, Schumann M, Ullrich R, Villalta D, Volta U, Catassi C, Fasano A, "Spectrum of gluten-related disorders: consensus on new nomenclature and classification,” BMC Med, 10, 13, Feb 2012.

[16] Sanders DS, Aziz I, "Non-celiac wheat sensitivity: separating the wheat from the chat!” Am J Gastroenterol, 107, 1908-12, Dec 2012.

[17] Freeman HJ, "Detection of adult celiac disease using duodenal screening biopsies over a 30-year period," Can J Gastroenterol, 27 (7), 405-8, Jul 2013.

[18] Tjon JM-L, van Bergen J, Koning F, "Celiac disease: how complicated can it get?” Immunogenetics, 62 (10), 641-51, Oct 2010.

[19] Soares FLP, Matoso RD, Teixeira LG, Menzes Z, Pereira SS, Alves AC, Batista NV, de Faria AMC, Cara DC, Ferreira AVM, Alvarez-Leite JI, "Gluten-free diet reduces adiposity, inflammation and insulin resistance associated with the induction of PPAR-alpha and PPAR-gamma expression," J Nutr Biochem, 24 (6), 1105-11, Jun 2013.

[20] Roberts, Jr. WA, “Gorging on gluten-free,” Prepared Foods, 182 (6), 31-6, June 2013.

[21] Kent PS,”Is going gluten free the next fad diet?”, J Renal Nutr, 23 (2), e47-e50, Mar 2013.

[22] Copelton DA, Valle G, "You don't need a prescription to go gluten-free: the scientific self-diagnosis of celiac disease," Soc Sci Med, 69 (4), 623-31, Aug 2009.

[23] Fleming SA, Gutknecht NC, "Naturopathy and the primary care practice," Prim Care, 37 (1), 119-36, Mar 2010.

[24] García-Manzanares A, Lucendo LJ, "Nutritional and dietary aspects of celiac disease," Nutri Clin Pract, 26 (2), 163-73, Apr 2011.

[25] Shepherd SJ, Gibson PR, "Nutritional inadequacies of the glutenfree diet in both recently-diagnosed and long-term patients with coeliac disease," J Hum Nutr Diet, 26 (4), 349-58, Aug 2013.

[26] Tursi A, Elisei W, Giorgetti GM, Brandimarte G, Aiello F, "Complications in celiac disease under gluten-free diet," Digest Dis Sci, 54 (10), 2175-82, Oct 2009.

[27] Miranda J, Lasa A, Bustamente MA, Churruca I, Simon E, "Nutritional differences between a gluten-free diet and a diet containing equivalent products with gluten,” Plant Food Hum Nutr, 69 (2), 182-7, Jun 2014.

[28] Newell A, Phillips C, Whatcom County Community Health Improvement Plan, Whatcom Community Foundation, 2013. Available:

http://www.co.whatcom.wa.us/health/community/pdf/whatcom_co unty_chip_11042013.

[29] Leffler DA, Dennis M, George JBE, Jamma S, Cook EF, Kelly CP, Schuppan D, "A validated disease-specific symptom index for adults with celiac disease," Clin Gastroenterol Hepatol, 7 (12), 1328-34, Dec 2009.

[30] Ghoshal UC, Mehrotra M, Kumar S, Ghoshal U, Krishnani N, Misra A, Aggarwal R, Choudhuri G, "Spectrum of malabsorption syndrome among adults \& factors differentiating celiac disease 
and tropical malabsorption,” Ind J Med Res, 136 (3), 451-9, Sep 2012.

[31] Volta U, Villanacci V, "Celiac disease: diagnostic criteria in progress,” Cell Mol Immunol, 8 (2), 96-102, Mar 2011.

[32] Vilppula A, Kaukinen K, Luostarinen L, Krekelä I, Patrikainen H, Valve R, Luostarinen M, Laurila K, Mäki M, Collin P, “Clinical benefit of gluten-free diet in screen-detected-older celiac disease patients,” BMC Gastroenterol, 11, 136, Dec 2011.

[33] Carroccio A, Mansuelo P, Iacono G, Soresi M, D’Alcamo A, Cavataio F, Brusca I, Florena AM, Ambrosiano G, Seidita A Pirrone G, Rini GB, "Non-celiac wheat sensitivity diagnosed by double-blind placebo-controlled challenge: exploring a new clinical entity,” Am J Gastroenterol, 107 (12), 1898-1906, Dec 2012.

[34] Singh P, Makharia GK, "Non-classical celiac disease: often missed,” International Journal of Celiac Disease, 2 (3), 76-85, Sep 2014.

[35] Schaefert R, Hausteiner-Wiehle C, Häuser W, Ronel J, Hermann M, Hennigsen P, "Non-specific, functional, and somatoform bodily complaints,” Deut Ärzteblatt International, 109 (47), 80313, Nov 2012.

[36] Soler JK, Okkes I, "Reasons for encounter and symptom diagnoses: a superior description of patient's problems in contrast to medically unexplained symptoms (MUS)," Fam Pract, 29 (3), 272-82, Jun 2012.

[37] Kim SE, Chang L, Overlap between functional GI disorders and other functional syndromes: what are the underlying mechanisms?” Neurogastroent Motil, 24 (10), 895-913, Oct 2012

[38] Peek CJ, Baird MA, Coleman E, "Primary care for patient complexity, not only disease," Fam Syst Health, 27 (4), 287-302, Dec 2009.

[39] Torabi MR, Tao R, Jay SJ, Olcott C, “A cross-sectional survey on the inclusion of tobacco prevention/cessation, nutrition/diet, and exercise physiology/fitness education in medical school curricula,” J Natl Med Assoc, 103 (5), 400-6, May 2011.

[40] Adams KM, Kohlmeier M, Powell M, Zeisel SH, "Nutrition in medicine: nutrition education for medical students and residents," Nutri Clin Pract, 25 (5), 471-80, Oct 2010.

[41] Kushner RF, Van Horn L, Rock CL, Edwards MS, Bales CW, Kohlmeier M, Akabas SR, "Nutrition education in medical school: a time of opportunity," Am J Clin Nutr, 99 (5), 1167S-73S, May 2014.

[42] Rodrigo L, Blanco I, Bobes J, de Serres FJ, "Clinical impact of a gluten-free diet on health-related quality of life in seven fibromyalgia syndrome patients with associated celiac disease,” BMC Gastroenterol, 13, 157, Nov 2013.
[43] Mahadev S, Simpson S, Lebwohl B, Lewis SK, Tennyson CA, Green PHR, "Is dietician use associated with celiac disease outcomes?” Nutrients 5 (5), 1585-94, May 2013.

[44] Herman ML, Rubio-Tapia A, Lahr BD, Larson JJ, Van Dyke CT, Murray JA, "Patients with celiac disease are not followed up adequately,” Clin Gastroenterol Hepatol, 10 (8), 893-99, Aug 2012.

[45] Bouchez-Mahiout I, Pecquet C, Kerre S, Snégaroff J, RaisonPeyron N, Laurière $M$, "High molecular weight entities in industrial wheat protein hydrolysates are immunoreactive with IgE from allergic patients,” J Agricult Food Chem, 58 (7), 4207-15, Apr 2010.

[46] Dewar DH, Donnelly SC, McLaughlin SD, Johnson MW, Ellis HJ, Ciclitiri PJ, "Celiac disease: management of persistent symptoms in patients on a gluten-free diet," World J Gastroenterol, 18 (4),1348-56, Aug 2012.

[47] Nachman F, del Campo MP, Gonzalez A, Corzo L, Vazquez H, Foggia C, Smecuol E, Sanchez MIP, Niveloni S, Sugai E, Maurino $\mathrm{E}$, Bai JC, "Long-term deterioration of quality of life in adult patients with celiac disease is associated with treatment noncompliance,” Digest Liver Dis, 42 (10), 685-91, Oct 2010.

[48] Zanini B, Lanzarotto F, Mora A, Bertolazzi S, Turini D, Cesana B, Donato F, Ricci C, Lonati F, Vassallo F, Carcella C, Lanzini S, "Five year time course of celiac disease serology during a gluten free diet: results of a community based "CD-Watch" program. Digest Liver Dis 42 (12), 865-70, Dec 2010.

[49] Valitutti F, Barbato M, Cucchiara S, "Letter: coeliac disease and ischaemic heart disease-a true risk factor?” Aliment Pharmacol Ther, 37 (11), 1116-7, Jun 2013.

[50] Gupta RS, Kim JS, Barnathan JA, Amsden LB, Tummala LS, Holl JL, "Food allergy knowledge, attitudes and beliefs: focus groups of parents, physicians and the general public. BMC Pediatrics, 8, 36, Sep 2008.

[51] Gupta RS, Springston EE, Kim JS, Smith B, Pongracic JA, Wang $\mathrm{X}$, Holl JL, "Food allergy knowledge, attitudes, and beliefs of primary care physicians,” BMC Pediatrics, 125 (1), 126-32, Jan 2010a.

[52] Gupta RS, Springston EE, Smith B, Kim JS, Pongracic JA, Wang $\mathrm{X}$, Holl JL, "Food allergy knowledge, attitudes, and beliefs of parents with food-allergic children in the United States," Pediatr Allergy Immu, 21 (6), 927-34, Sep 2010b.

[53] Kohout P, “Nutrition in celiac disease,” International Journal of Celiac Disease, 2 (3), 115-7, Sep 2014.

[54] Crowe SE, "Management of celiac disease: beyond the gluten-free diet,” Gastroenterol, 146 (7), 1594-6, Jun 2014. 